\title{
NOVELA ESPAÑOLA DEL SIGLO XXI
}

\author{
José María POZUELO YVANCOS
}

(Madrid: Cátedra, 2017, 373 págs.)

Consagrado en el campo de la teoría y la crítica, el profesor José María Pozuelo Yvancos vuelve a convertirse en precursor de esclarecedoras interpretaciones literarias, en este caso con el ensayo titulado Novela española del siglo XXI. Pese a no ser la exhaustiva configuración de un canon el objetivo de este estudio ${ }^{1}$, se vislumbran en él las ideas imperantes más representativas en el recorrido por los distintos cauces de la narrativa desarrollados en España desde el comienzo de este siglo. Encontramos en estas páginas agudos estudios monográficos dedicados a las novelísticas de Luis Mateo Díez, Javier Marías, Enrique Vila-Matas y Arturo PérezReverte (que ocupan más de la mitad del conjunto del libro que nos es objeto), unidos a los capítulos dedicados al análisis de las obras de Manuel Longares, Soledad Puértolas, Ignacio Martínez de Pisón, Ricardo Menéndez Salmón y Clara Usón. A todos ellos se suma la revisión de distintas novelas en las que la Guerra Civil ocupa un lugar protagonista para la construcción de las ficciones narrativas, incluyendo ilustrativos ejemplos de representación a través de su canalización en las obras de Javier Cercas y Almudena Grandes. Un último capítulocerrará este panorama literario de principio de siglo con la introducción del más reciente quehacer narrativo en el que los jóvenes novelistas españoles enfrentan e interpretan la crisis económica europea.

1. Algunos de los estudios incluidos son consecuencia de cursos de doctorado, principalmente los desarrollados en el Graduate Center de CUNY (City University of New York) y en el Colegio San Luis, centro de Conacyt en México. 
Gracias a la prolijidad de las citas textuales convocadas que sostienen las perspicaces lecturas expuestas, los capítulos monográficos incluidos ofrecen al lector el estudio de novelas de gran calado literario que, desde el año 2000, han visto la luz en el panorama narrativo español. Entre ellos, merecen especial atención las aportaciones teórico-críticas en torno a la obra de Javier Marías; su consecución de la "voz en el tiempo" queda revelada como un complejo proceso en el que el mundo ficcional de engaños y traiciones silenciadas se percibe como una vivencia del yo doliente, "un yo verificándose, siendo, ejecutándose" (63). La abolición del tiempo logra en la obra de Marías una novedosa "presentez enunciativa" que define la voz narradora de este autor. Del mismo modo, la diseminación del concepto de la identidad en la narrativa vila-matiana constata el valor de la categoría acuñada anteriormente por Pozuelo Yvancos "figuraciones del yo"', la que, unida al quijotismo lúcidamente argüido en el texto de $\mathrm{El} \mathrm{mal}$ de Montano y a la distancia irónica continuamente percibida, configuran la poética de Enrique Vila-Matas, cuyo elemento vertebrador no es otro que el de la literatura misma. Existen otras muestras del discernir teórico que sabiamente queda demostrado en las páginas de Novela española del siglo XXI. Por citar dos ejemplos más, de la lectura de la fábula creada por Luis Mateo Díez en el reino de Celama se extrae la universalidad de un "Territorio de la Imaginación" anclado en el tiempo a la manera del pueblo de Comala o el condado de Yoknapatawpha faulknianos. De la sutil sabiduría narrativa de El Tango de la Guardia Vieja de Pérez Reverte destaca la apreciación de las "semillas narrativas" alojadas en textos casi elípticos que, no obstante, brotan gracias a la mirada suspicaz con la que se analizan.

Tanto en dichas lecturas como en las correspondientes a los capítulos restantes, encontramos una selección de textos en la que se adivina una mirada experta que reúne la poética de cada uno de los novelistas tratados, exaltando sus particularidades en el proceso de creación literaria. Pozuelo Yvancos consigue desmenuzar la voz narrativa propia de estos autores del siglo XXI y su evolución a lo largo de sus obras, revelando la unidad de ciclos narrativos de cuya percepción es indudablemente pionero, como ha sido el caso del ciclo de Deza de Javier Marías o de la "tretalogía del escritor" de

2. Categoría analizada en sus libros Figuraciones del yo en narrativa.: Javier Marias y E. Vila Matas. Nueva York, Valladolid, Catedra Miguel Delibes, 2010 y en su monográfico sobre la autobiografía (De la autobiografia: teorías y estilos, Barcelona: Crítica, 2006) 
Vila-Matas. Los meticulosos análisis que abordan las cuestiones esenciales del funcionamiento de la ficción y los procedimientos empleados por los narradores recientes captan la dicotomía en la que la verdad literaria supera los lindes de la verdad histórica. En definitiva, los capítulos monográficos que componen este libro en casi su totalidad profundizan en las poéticas narrativas tomadas de la base de los textos novelísticos, traídos con la intuición que siempre se reconoce en las investigaciones previas del autor.

Un segundo núcleo temático que hace de este estudio una aportación significativa sobre las vías más representativas de la novela del siglo XXI español es la dedicada al tratamiento de la Guerra Civil. Introducidas por la reflexión de las causas que explican su proliferación y su buena acogida, este tipo de obras responden a motivaciones como el protagonismo de los testimonios del yo o la inacabada dicotomía de las dos Españas. La memoria narrativa de dicho acontecimiento culturalmente trascendental se canaliza en la literatura por los textos autobiográficos y los textos de ficción principalmente novelísticos. Reconocida la importancia de la vía memorialista, así como la de la presencia del enfrentamiento bélico en forma de germen contextual que da pie al tratamiento de otros asuntos en el campo de la ficción, el objeto de estudio en estos capítulos serán aquellos textos en los que la presencia de la Guerra Civil se comporta como pilar para la construcción de la novela. Gracias a la pluralidad de las obras que forman el corpus de este capítulo, distinguimos la variedad de formas estructurales que se manifiestan añadiendo a las acuñadas en la tesis de Fernández Prieto nuevas fórmulas; entre ellas destaca la "Proyección hacia el presente", cuya expresión queda patente en novelas como El hijo del acordeonista de Bernardo Atxaga, Los libros arden mal de Manuel Rivas o La higuera de Ramillo Pinilla. A ello se suma el análisis pormenorizado de las revisiones narrativas de la Guerra Civil de Javier Cercas, donde de los incidentes anecdóticos se extraen significaciones de gran fuerza simbólica en el dispositivo de esta "novela haciéndose", y la llevada a cabo por Almudena Grandes, quien dentro de la horma del realismo, arma una narración que desde una mirada interna busca "el aprendizaje de una conciencia" (281).

Por último, excediendo de nuevo los límites de lo exclusivamente textual, el duodécimo capítulo se abre con la introducción a la nueva narrativa española teniendo en cuenta las relaciones del actual momento socioeconómico y las direcciones tomadas por la novela que se escribe 
hoy en España. Uno de los valores añadidos a la totalidad de este libro es la inclusión de un corpus excepcionalmente actualizado -teniendo en cuenta novelas publicadas incluso en 2017- y, más aún, la capacidad de abordar el presente novelístico con la sagacidad y previsión necesarias para un fenómeno que fluctúa en la inmediatez del presente. De entre la multiplicidad narrativa nacida de nuevos movimientos literarios, Pozuelo Yvancos consigue discernir aquellos productos comerciales efímeros, de aquellas obras que gozan de una mayor transcendencia y proyección. En estos títulos pertenecientes a la "novela de la crisis", el autor contempla dos direcciones que se contraponen: el nuevo realismo (cuyos matices se analizarán a partir de seis títulos entre los que se encuentra La trabajadora de Elvira Navarro, Entre los vivos de Ginés Sánchez o La edad media de Leonardo Cano) y las "formas de la distopía" (a las que accedemos a partir de otros seis títulos como La mano invisible de Isaac Rosa, Las efímeras de Pilar Adón o El sistema de Ricardo Menéndez Salmón). Ambas igualmente críticas, ofrecen en sus lecturas un caleidoscopio de estilos en el que el neoexistencialismo, el esperpento, los mecanismos redentores del Arte como fuerza transformadora o la conjunción de voces narrativas son sabiamente interpretadas en estas últimas páginas.

A partir de la composición de una investigación sutil, penetrante y crítica que da entidad a las obras de autores unidos por un tiempo, Pozuelo Yvancos cumple con este libro el desafío que supone la teorización sobre las vías más actuales de la narrativa. La lectura reflexiva de cada una de las más de cincuenta obras dota a este libro de una visión panorámica de la novela española del siglo XXI, no a partir de una perspectiva teórica alejada de los textos literarios, sino al contrario, gracias a su comprensión y acercamiento individualizado y autónomo en el que quedan analizadas las idiosincrasias que sirven de axioma a las distintas vías estilísticas de la narrativa actual. Aunque alejada de su labor como reseñista, es esta una investigación en la que Pozuelo Yvancos logra una vez más comunicar la teoría de la literatura con la lectura crítica de los textos, reuniendo los puntos de debate ante los que se encuentra el público actual al tiempo que arroja luz sobre la creación artística gracias al manejo que como teórico y avezado lector demuestra poseer.

María José García-Rodríguez

Universidad de Murcia 